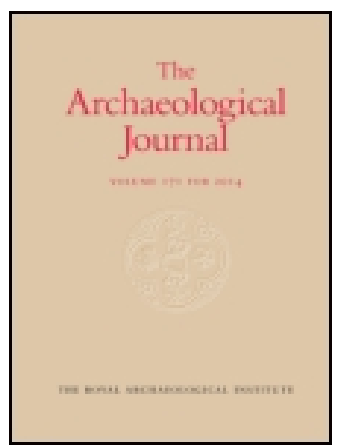

Archaeological Journal

\title{
Notes on Egyptian Colours
}

\section{F. C. J. Spurrell}

To cite this article: F. C. J. Spurrell (1895) Notes on Egyptian Colours, Archaeological Journal, 52:1, 222-239, DOI: 10.1080/00665983.1895.10852669

To link to this article: http://dx.doi.org/10.1080/00665983.1895.10852669

曲 Published online: 16 Jul 2014.

Submit your article to this journal $₫$

a)

View related articles $\sqsubset$

里

Citing articles: 2 View citing articles $\sqsubset$ 


\section{NOTES ON EGYPTIAN COLOURS.}

By F. C. J. SPURRELL.

The notes which follow are a combination of several papers contributed to the Institute during the last few years. They are mainly the consequence of opportunities offered by Professor Flinders Petrie's kindness in permitting an examination of specimens found by him ; but many other collections have also been studied.

Mr. Petrie's specimens have the special value of being correctly dated.

The chief of the notes are devoted to three periods in the older Egyptian history - the fourth, the twelfth, and the eighteenth dynasties. Though this involves some repetition the examination of each series separately helps to mark chronological changes.

\section{Colours from Medum. III. and IV. Dynasty.}

The examination of a group of tombs at Medum is of especial interest as to them belong the earliest dated painting known, that of Senefru, the first king of the fourth dynasty; they therefore represent the third dynasty also.

To the northward and eastward of the step pyramid is a collection of mastaba tombs whose upper chambers have furnished the colours under consideration, the chief of these are Rahotep's and Nefermat's.

The surface of the stone on which the decoration was placed was worked smooth by means both of copper chisels and flint flakes. The colours were laid on the stone by brushes giving results both fine and regular. Some of the red and yellow were rubbed on by the aid of a cloth until they adhered, as is seen by the smudge spread irregularly outside the margin of the figure delineated. The process was similar to the present use of black lead and blacking for boots. In some cases the colours are non-adherent the medium having decayed, in 
others it is fixed and still offers some resistance to its removal by water.

Some of the paintings were on a specially prepared ground. The brick was covered with a layer of mud and cut straw about $1 \frac{1}{n}$ inches thick, on this was a coat of lime and gypsum, burnt together and mixed with fine $t i b n$ from $\frac{1}{3}$ to $\frac{1}{2}$-inch thick, a thin coat of white plaster $\frac{1}{20}$ inch thick finished the surface. The better paintings are very fine and lowest in position, higher up they are larger in size and not so well finished. The whole height of the frescoed wall was more than 23 feet. The outlines were first traced with a faint red. ${ }^{1}$

The medium employed in the paintings is difficult to determine so thin is the layer of colour. All is removable by water but not with equal ease. Notwithstanding the smallness of the amount available for examination, the result showed that the same materials were used as those described later in the twelfth dynasty section.

The north and south chambers of Nefermat's tomb, however, show the most peculiar mode of colouring the numerous figures and hieroglyphs. The outlines and spaces within them have been chiselled out of the stone, by metal chisels, commonly to the depth of one centimetre, and into these cavities has been inserted a paste which was then finished off flush with the general surface and carefully smoothed. The colours were first described by Mariette as giving "un eclat extraordinaire" to the general appearance of the tomb. Nefermat's figure has immediately in front of its face an inscription evidently referring to this unusual decoration that "he made this to his gods in unspoilable writing." However, it turned out to be very spoilable, and Mariette described it :

"Ces pâtes ne sont pas partout egalement conservees. Le rouge puis le noir ont presque toujours disparu, et ce qui en reste s'éffritte facilement sous la main; mais le blanc, le jaune, le vert et surtout le bleu, sont encore tres resistants." Besides the inability of the paste to hold itself together which has caused this destruction, its non-

${ }^{1}$ In Nefermat's tomb a length of painted mud facing had in course of time elipped bodily off the wall and fallen, a specimen was however secured and the surface transferred to slate, such a piece is in the $S$. K. Museum. 
adherence to the stone gave much trouble even at the outset of the operation. An endeavour to overcome this was made by dividing the larger excavated areas into a number of deeper cells separated by cross ridges of stone. Holes were drilled diagonally beneath these ridges so as to meet and form tunnels for complete loops of the paste to hold by. ${ }^{1}$

The outer edges of the figures were undercut and thus the paste was keyed in. The irregularities in the general surface of the stone were levelled up with plaster which was excavated for figures as if it were stone. Where the details of the figures required it the pastes themselves were excavated to varying depths and suitably coloured pastes inserted in them. No painting is found over the pastes however fine the lines, except that over a white surface a proposed line was marked out in red, and sometimes when very narrow left unexcavated by accident.

Many of the levels of excavation are different without apparent cause; and very narrow lines are deep, variously $U$ or $V$ shaped, and not undercut.

Many of the pastes have now no cohesion at all, yet they must once have had some material to keep them together, for when examined they are no better than coloured sand. The primary idea seems to have been stucco coloured with added material as most of the examples show. In a specimen of pulverulent red, the commonest kind, about half consisted of stucco the other half sandy red and yellow ochre. Even if the plaster was well made so large a diluent of sand would prevent its setting. Therefore the workmen were put to a difficulty in finding a binding material. Interspersed through most specimens are very small globules and ovoid masses of a resin which are, however, absolutely and completely separable from the mass and which in no way help to bind it together; but where white colour which is mostly stucco is used no globules are found. The little globules of resin are heavy and insoluble in water. Originally the resin was finely powdered and mixed with

${ }^{1}$ Something like this was employed at Mugeyer, Chaldea, where plates of marble alabaster and agate were bored sideways at the back until a loop was formed, so as to enable the cement in which they were set to hold them to the walls. J. E. Taylor, Journal $R$. Asiatic Soc., xv. 411 . 
the paste, but being found insoluble the mass was subjected to heat as high as boiling water perhaps in order to dissolve it, but no more could be accomplished than to bring the resin to a globular form when it was sufficiently softened to permit this. The globular arrangement shows that the resin was insoluble in water therefore it could not have been gum arabic. Neither was it partially soluble, so that it could not have been myrrh, or any of the bdelliums, ammoniac, olibanum, etc., but must have been a true resin such as water cannot dissolve at all. It could not have been a resin which did not soften at the heat of boiling water because the little spheres were perfectly smooth; this cannot occur unless the solid materials are held in suspension leaving perfect freedom of motion among their particles sufficient for this but not to separate from the paste altogether. The granules are globular, they have a little pit or depression at one point. The little pit was caused by the contraction of the interior. The outer shell which had lost its volatile portion and become rigid instead of flattening sunk in at one little round spot. The globules are of a dark brown colour without, and a bright yellow within. Neither the outer nor the inner part is transparent and clear. It will not soften in boiling water, indeed its melting point is so high that it does not liquefy until it begins to char. This resin has therefore changed its qualities since the day it was used when it must have resembled so far as softness goes new mastic.

I have made experiments with pastes similarly constituted to the ancient ones combining with them finely powdered gums, gum resins, and true resins. With the latter I got similar forms, with mastic sandarach and well dried coniferous resins, pits and all-but of course they were transparent and easily soluble. But with myrrh, olibanum, ammoniac, and the bdelliums with others which emulsify in water, pitted globules could not be obtained.

In making these experiments I have to acknowledge, with many thanks for their constant kindness, the assistance of Mr. E. M. Holmes and Mr. J. R. Jackson of Kew, in providing me with specimens of various gum resins etc. for trial.

Perhaps mastic comes nearest to the old example. Q 2 
Mastic also it will be remarked becomes very dark by age and much more difficult to melt. Experiments have been made with a specimen over 200 years old, but between that and 6000 , leaves room for changes of which we know nothing. There may also have been other resins soft when used in old Egypt, now known only as hard ones. There may also have been a further experiment tried by the ancients, and the powdered product of a mixture of resins fused together, thrown into the pot. As all this experimenting must have had a cause it may be suggested that the idea came from mixing the pastes with gum arabic or myrrh or other emulsifying gum, but that through ignorance or carelessness, other resins got mingled with or substituted for them which were intractable and valueless. Anyhow some remedy was necessary and was applied. For there are some specimens of red paste which are very hard, their hardness is greater at the surface and penetrates to various depths, sometimes quite through the mass to the stone. After extraction by boiling water this material is found to be a colloid and answers to tests for altered gelatine. It is sticky, though not capable of making jelly and is in every respect the same as an extract made by boiling some bones of the same age (IV. Dynasty) and from the same place. It appears then that the gelatine kept until liquid was applied to the dry surface and allowed to soak in, thus overcoming the difficulty in part.

The examination of the colours themselves shows that some of the red was ground hæmatite, but yellow ochre and yellow marl burnt were also used. The yellow colours are wholly ochre but in the forms mostly of clay or marl in the pastes. In the paintings the ochre was probably prepared from the marl which underlies the desert sand around Medum, it is a fine colour and exactly that found on the walls. If purer pockets of it were not naturally found, it could, when steeped in vinegar or sour wine or beer and so removing the calcium carbonate, be made to yield about one-fifth of its weight of a fine colour. Probably it was so prepared as no natural colour has been found of so fine a texture as it becomes by this means, and which is like that in use.

The white is gypsum raw and burnt, black is lamp 
black or the soot from resinous wood, a circular cake of this was found in Rahotep's well $\frac{1}{2}$ inch by $1 \frac{1}{2}$ inch in diameter.

Green is pure malachite; as however, this was scarce, the bottoms of the deep excavations were filled with the yellow marl, and the green placed on that. A lighter tint was made by mixing gypsum with it. Even the red paste was sometimes underlaid by some plain plaster for the like economical purpose.

It is to be regretted that there was no opportunity for examining the blue tints which are, however, in some cases bright, but in most cases are hardly blue but grey or slate coloured. A shell used as a palette was found in an undisturbed well of a mastaba between Ranefer and Rahotep which has the remains of a beautiful blue smeared over its interior. This was pure chessylite, and on Ranefer mummy, now in the Royal College of Surgeons Museum, the mouth and eyebrows are painted on the fine cloth which covers the face in pure chessylite. It looks green from age and staining which is an accident.

Though chessylite was used at this time yet frit was manufactured and employed, and there are several examples known. One, however, of the IV. Dynasty recently acquired by Mr. Petrie, of which he permitted some to be detached, gave unmistakable signs that it was a copper frit of medium depth of tint of great purity.

\section{Colours from Kahun, XII. Dynasty.}

Some fragments from the wall decorations of Usertsen's Temple at Kahun show the colours well preserved; they are brilliant and clear and are laid on hieroglyphs and figures. The red is ground hæmatite (rarely) and burnt yellow ochre. The numerous pieces of granular hæmalite found, showed by their shape that they had been ground in water, this being the only way of reducing it to a sufficiently fine powder. Many of their faces are flat and many curved, the latter being caused by the stone having become hollow on which the rubbing had been long conducted, not from the intentional use of a concave surface. The yellow is ochre very finely levigated. The greens are copper silicates (chrysocolla) or malachite, the 
latter predominating and the hue alike in all. Blue is invariably copper frit to which full consideration is given later on.

The quality of the blue frit is very unequal, some is dull and transparent, that is murky and non-reflective of light, while some is all that could be wished; but neither the very pale colour nor the violet blue employed in later work is met with. Two specimens of this colour prepared for use and still in the pots were found in town, but they were careless mixtures of good blue and greenish frit. All the blues are very coarse powders the separate grains of sand employed still remaining unground.

The colours are spread over very carefully sculptured and prepared stone, the surface in some instances having been covered with a wash of transparent medium which is still perceptible. There is great refinement in the work and marvellous care in the execution. The lines were usually regulated by the sculptor and did not require sketching by the colourists. The reds and yellows were often laid by brushes in thicknesses which permits some reflection from the stone beneath thus increasing its brilliancy. Greens were laid on very thickly with a coarse brush so that they mostly have a bad edge unless subsequently trimmed. The surfaces on which the blue was laid were first covered with green where finish was required. The green before drying was pressed down by a bone or metal instrument so that a smooth and polished surface was given to it, the irregular edges clearly evince this pressure. Blue was painted in thick layers in consequence of the size of the grains, or even placed on the stone with a spatula, but in the finer work it is painted over the green not so much to economise the blue as to form a cushion for the coarser grains to bed into, so that the smoothing or burnishing process might give a fine surface. The pressed-out edges of the blue were trimmed off and a very fine red line painted at the junction of two colours. Finally a very fine red line truly microscopic in width and scarcely perceptible to the observer was carried round all margins and parting lines. In the routine of work the red and yellow surfaces were first laid on by friction then the green and blue. White, red, and black touches were painted over the green but as that colour 
was absorbent the lines are often faint. Some fine lines of blue marking the divisions of the palm branch hieroglyph are but one hundredth of an inch wide and regularly curved, a marvel of execution where the blue was of a coarse grain necessarily, for if ground too fine it became too pale. Black is lamp black, but among some colours of the same date sent from Beni Hassan by Mr Percy Newberry the black was found to be Pyrolusite [Wad] the remainder were similar to the Kahun examples.

In the case of the better preserved pieces of stone which are uninjured by efflorescing salts the colours adhere firmly and there is clear evidence that the medium still remains. They are unaffected by plain water cold or hot, even soap does not remove them as would have been the case if held by mere pressure. But from the small quantity on which experiment can be made testing is difficult. After numerous tests had been applied, all pointing to one result, a piece of stone was found on which the red colour had been smudged over the wished for outline, and over the smudge a thick daub of the medium mixed with a little white had been laid to hide it.

This spread had became of a light brown hue and consisted of powdered limestone held by a horny semi-transparent substance which could be flaked off in minute pieces. These were insoluble in water hot or cold, but charred with heat and burnt white on continued calcination; heated in a closed tube an alkaline vapour was given off restoring the blue colour to red litmus paper: weak muriatic acid dissolved out the stone and left the medium which was dissolved by strong muriatic acid; this also liberates the particles of frit in other cases. There can be little doubt that it is albumen. It cannot be gelatine or any resinous gum as it is insoluble in all the usual solvents for such except in a very minute degree. A peculiar condition, somewhat glossy, of the surface of the stone around other paintings was found to be caused by a dressing of this albumen over surfaces now wholly devoid of colour. This suggests the probability that some organic colour now completely faded once tinted the surface. Nor is this unlikely, for frequently grey, dark and light, and pale washes of greeny blue body colour are met with as backgrounds for throwing up the hieroglyphs, 
etc., or it may have been a dressing to fill up the pores of the stone and thus procure adhesion of the colour. The great age of these remains may account for much of the obstinacy which the albumen exhibits. The long exposure to the sun and weather on the building or after lying on the sand was quite sufficient for its coagulation and consequent insolubility as has been found by experiment. It has also been found that if eggs--duck or goose or other, be whipped and allowed to stand, either with or without the yolk they become manageable as a medium in one or two days, they form a thick compound with similar colours which behaves just like the Egyptian ones. If exposed to a high temperature either in the sun or before the fire which, however, need not be greater than the hand can bear, for a few hours or longer, the egg becomes insoluble in water and the colour cannot be washed off. It is not necessary that the yolk should be excluded, rather it gives the advantage of a slight varnish when the oil is oxidised. This hardening takes some time during which dust may adhere to the oily surface; thus may be explained why on many paintings in Egypt of all dates a minute layer of impalpable dust coats the colours making them more or less dull, sometimes completely cloaking them and difficult of removal-which especially affects the blues. The yolk of an egg may be green when mixed with blue frit and first laid on, but a short exposure to light and heat bleaches it completely and leaves a pure blue. There appears to be no doubt left that all the colours which I have examined having the above characters had egg albumen for a medium, and this extends from Senefru's time to that of the Romans, although of course gum arabic was largely used and other easily soluble media of the nature of gelatine.

Colours from Tell el Amaria, XVIII. Dynasty.

These are from the actual factory and paint shops. With them are included specimens very similar from Gurob of the like date.

The ochres form a large and varied selection. Their

${ }^{1}$ For description of site, see Petrie. Tell el Amarna. 1894. 
constitution shows that some have come from localities not in the immediate neighbourhood of one another, while others differ sufficiently to show at once that they come from a wholly different and presumabiy distant locality. It is quite clear that a diligent search was regularly kept up for the supply of these ochres. It is not known where they were got in any quantity. A yellow marl is not unfrequently found not far below the surface which by decalcification may be made into a fine colour. Many of the yellows are mere clays often containing various sands, mica, etc., by the study of which a clue has been found for identifying which of the natural materials were burnt into reds. For an extensive variety of reds are the result of calcining or burning the yellows. The crude ochres were burnt in mass, being kept at a red heat for some time and afterwards ground in water. The inside of only a few lumps show any change on hearing. The number of specimens of red whether natural or baked amounted to several dozen, all were burnt with two exceptions, granular hæmatite and a red clay. The burnt and raw yellows were often ground together and produced fine tints. With the aid of gypsum varying shades of pink were obtained of a softuess resembling closely the madder pinks of later date and which require to be tested to determine that they are not vegetable colours. Some of the colours on the walls could be distinctly identified with those found in the shops. One of the natural reds consisted of masses of a fine sandy material from the surface washed by rain into a crack or fissure. It consists of fine layers of red and yellow, and has a bright pink appearance. This specimen is interesting as it was the same material as was employed for the red pastes in Senefru's time.

Ochre yellow fine as it was, was exceeded by orpiment. In the Amarna paintings there is one of King Akhenaten, his queen, and two little princesses with attendants. The flesh is illuminated with a minute portion of orpiment, especially on the high lights where it certainly appears more clearly than on the shaded parts which were treated by a wash of dull red. This perhaps is the earliest examples of shading known. A superficial smear of imperfectly powdered orpiment was placed over the 
earrings as an afterthought apparently to brighten them up. The orpiment in this case was imperfectly powdered and somewhat sparkling and it was only applied to royalty and not to the attendants. Orpiment was a rare colour, and was ground for use at this period as wanted, and not in large quantities. Some was ground very fine, crude and ground being found at Kahun as well as Gurob. Realgar which is commonly found with it was sparingly used being ground together with it. But realgar alone has not been found on any painting. Orpiment was applied to stone and pottery, sometimes covering a comparatively large surface.

White colour consisted of gypsum in ground crystals and efflorescent powder. Black was lamp black in every case.

Both the red and yellow prepared pigments were made by grindirg on a hard stone. Some of the pieces are ground perfectly flat but others have convex surfaces. This was the result of wear from using the same stone for a long while and was not intentional nor advantageous. It has been suggested that the colours were ground on the interior surface of a large earthenware pot. As, however, a large quantity is found to be ground off the pot by this means leaving evidence of the result in the finished product, it could not have been the method employed, for in no case was earthenware powder found in the colours red, yellow or blue, in which latter case it would have been highly detrimental. In grinding the best effect is obtained by using a large vessel full of water with a flat stone in it whose surface is just lapped by the water. After rubbing, the water was poured off to settle and the refuse pieces thrown aside, though sometimes the whole was allowed to settle until the water was clear; examples of both kinds have been found.

The specimens of blue from Amarna and from Gurob range from a very pale sky colour to a deep bluish violet; in the case of frits a pale lilac was found at Amarna. In the remains from Amarna and Gurob many small specimens of natural blues and greens were found which had been collected for trial but none show signs of use. They were blue and green carbonates of copper, also in the form of a kind of sandstone. Amazon stone, chryso- 
colla, one particular kind having masses of a bright blue amongst it, various schistose and slaty rocks, some of which are stained by infiltration of copper ore, but they were not abundant.

The pieces of frit were numerous and comprised all grades of success and failure in the manufacture. They with the other colours were found at Amarna in the workshops where they were made, furnaces, grinding and mixing being carried on at the spot. Frit consists of a mixture of silica, alkali, and copper ore. That it might be employed as a colour these were mixed in such proportions as to stand the heat necessary to accomplish the chemical change without fusing or becoming a glass, which when it nappened was always ill-coloured and useless. Although the furnace refuse of frit-making had not been found in sufficient quantity to determine all the details of procedure, the furnace floors were found which had been employed in glazing pottery, and in making enamel and glass as well as frit, for pieces of it were found in the remains. The white quartz pebbles of the floor were stained with the copper silicate.

It is evident that the materials after admixture were heated in deep pans. Mr. Petrie fourd pots with flat bottoms and upright sides, five inches high and seven across, sometimes larger. These were arranged on the furnace floor in rows somewhat apart, bottom upwards ; the bowls of frit sometimes flat bottomed, sometimes rounded, rested between their edges so that the furnace could be raked under them. Large quantities of the mixture were prepared at once and the large capacity was necessary to hold the swelled up material, for there was a considerable disengagement of gas when the copper ore had not previously been roasted as was sometimes done. They were of rough spongy pot and the alkali uniting with it caused a great waste at the edges so that often but a small mass in the centre actually remained for use, and the pots could never be used again.

The depth of the pans was also arranged to prevent the access of unburnt gases and vapours to the mass which might reduce the copper salt irregularly, and spoil the product, which frequently happened, not so frequently perhaps in the lighter colours as in the darker and more 
brilliant ones. It is unlikely that a batch of deep blue throughout was ever accomplished at the first trial in early days.

When the mass was finally broken up it was commonly found that part was green and part blue, mottled and shaded in a beautiful manner. Then the best parts were selected, ground, and re-heated in shallow pans which hardened and slightly intensified the frit, making it uniform. It formed cakes round in form, six or eight inches in diameter, and in thickness from one quarter to one inch thick. Cakes were found which had been formed in shallow hemispherical pans with another similar pan placed over the lower to press the cake out; the colour of the latter was lilac.

Green frit was sometimes a step in the process of making the blue which could then be arrested and the result employed. But green could also be made by employing sand highly stained with iron; the careless use of which ruined many a batch intended for blue. The greens were rarely used, being inferior to malachite.

The statement of Lepsius that the colour was cast into bricks is altogether wrong.

The silica was always quartz never flint dust. It was usually fine sand which, however, was difficult to procure free from iron. The quartz pebbles which were laid at the bottom of the furnace could be used as silica, for after being heated and thrown into water they became friable and could be pounded up. Their colour was a very pure white, specimens of frit made with this quartz were found. The alkali was soda, native potash from burnt reeds, etc., and limestone. The copper ore was always malachite, crude and roasted. The frit when finished ought to be finely granular, capable of breaking up into powder. It was ground under water on a flat stone hard enough to break up the silicate without perceptibly adding anything to the result. The stone could not therefore have been red pottery, as no trace of such has been seen in the perfect colour. The rounded worn surface was caused by stone hollowed by use. As grinding made the colour paler, the dark frits were well washed and reheated afterwards.

From the great quantities of frit used its manufacture 
must have been fairly well understood. There are difficulties, however, which made the success of the ancients really remarkable. With the pale frits the difficulties were least, a brisk red heat for a few hours was all that was needed and the colour did not readily spoil with continued heating. The pale and even the moderately dark colours could be made without lime and yet be a fine blue without any trace of the greenish tint so often associated with copper blues. But with the deep blue, purple, or violet a large proportion of lime is required and a great increase in the copper. The temperature must be sufficiently high for combination to proceed; but not too high or the whole becomes black or glassy; and this rather narrow range must be kept up continuously for many days, or if with intervals for a much longer period. The violet and lilac take an excess of lime. No cobalt has ever been found although that substance was used in blue glass making in the eighteenth dynasty and later.

The hues of the early frits that have come down to us are very similar, and from the fourth dynasty the object sought has been a brilliant blue of moderate depth. In later times numerous varieties were added, some by intention in manufacture, or some by admixture. After the nineteenth dynasty true blues were made but mostly a lower tone was affected, and strange combinations far removed from blue were in fashion, being sometimes little better than grey, or the powder of roofing slate. The fashion of the day compelled this equally with similar hues in glazes and glass.

Numerous examples of frit unground may be seen in the Egyptian departments of European museums of all dates, chiefly late, although no dates are affixed to them, so they are worthless for chronological purposes. There are cakes originally of large size in the British Museum, but a reference to the catalogue gives no particulars. A dozen balls found together are interesting however, they have the fine violet colouring of later periods and are probably Ptolemaic, but are interesting as showing the original of the forms of cakes introduced after into Italy. So little interest was taken in these that Belzoni did not recognise the material as mineral, but stated that some he came upon were an evidence that the old Egyptians 
made up cakes of indigo with sand after the manner that such were made in Egypt in his time. As already shown the manufacture was largly carried out in Upper and Lower Egypt from early times until the mediæval period, and the famous Egyptian blue had been exported to Europe and Asia Minor. At Tiryns it was employed on walls and floors. Though there is no evidence it was made in Greece so early as the fifteenth century B.c., or for many hundred years after, there is a probability it was so. There is plenty of evidence of its use on Greek buildings of early or later date, and in Etruria. ${ }^{1}$

Many Greek sculptures in the British museum still retain patches of the colours which have escaped the soft soap and hot water treatment they have suffered in order to rob them of the universal tints with which they were covered. It is needless to enumerate examples, for there is not anything there but what was once coloured, as is shown by the patterns still left on the marble by the protective action of the media which held the various paints.

Frit was early in use in Syria, but that it was first made in Syrian Phonicia and thence sent to Europe and exported to Egypt as lately asserted ${ }^{2}$ requires at least the proof that it was ever manufactured in Syria at all.

It was employed and apparently made in Mesopotamia. Some was found ground for use at Koyunjik which is now in the British Museum. It was early a subject of barter between Egypt and the East together with its superior lapis lazuli. Wherever Greek and Roman Colonies existed in the Mediterranean area it has been found extensively on building, sculpture, vases, ivory, etc. In England I have seen it at Silchester and in the Villa at Darenth lately opened up, all these, however, are of the pale cheap kind. It has been recorded as found in France.

1 See letter from Faraday in the Royal Institute of British Architects 1. 1842. On colours from Athens: he describes blue frit and blue carbonate of copper both laid on with wax. See also Penrose, F. C., Principles of Athenian Architecture. p. 59. note 1888. Gardner, E. A., Archæology in Greece, 1888, vol. x. of Journal of Hellenic Studies in Deltion, December, 1888, are remarks on the chemical constitution of Greek colours; Cros et Henry, and many more works.

${ }^{2}$ C. Diehl, Excursions in Greece. Art. Tiryns.

${ }^{3} \mathrm{H}$. Fontenay, Ann. de Chimie et de Phys., $\mathrm{v}$ series ii, 193, gives examples of Roman blue frit found at Bibracte with analysis. 
The later manufacturers only succeeded in producing the pale colour and then the use of it died out. There is no trace of it in any mediæval paintings being superseded by smalts of cobalt and lapis lazuli.

Notices of this blue are abundant in Lepsius, Metaux, traduit par Berend, 1877, who quotes one inscription of Thothmes III.

There are no accounts of it until Pliny's time, he [N.H. XXXIII. 57] mentions cœruleum which was mostly prepared in the wet way by means of cupreous salts, not always without the aid of plants also, but he says that coruleum was used on a surface prepared with clay for it could not bear lime-clearly it was not a silicate. In contrast to this he mentions another ccruleum, the Vestorian which had lately been introduced, which would lie on lime; this was frit of course. Vitruvius mentions its manufacture, saying it was made at Pozzuoli lately introduced from Egypt by Vestorius. Vitruvius, VII. 91. Theophrastus [deLapidibus XCVIII.], speaks of three places whence cyanus came, of which the Egyptian was the best, et.c. Perhaps Isidore of Seville [Origines, XIX, 17] is the latest who mentions it, he calls it Venetum cœruleum and says that in Italy it was made of Flos nitris and powdered sand, but that if burnt copper is added it becomes like Vestorian blue. ${ }^{1}$

Sir Humphry Davy in a paper in Phil. Trans. for 1815, " On Colours in Use by the Ancients," gives an account of the analysis of some blue frit from Rome and a receipt for imitating it. He was the first in recent times to imitate it. He describes it as cheap and easy to make, which was true, being a pale washed out colour as he performed the trial.

In Passalacqua's catalogue, p. 239, is an analysis of an Egyptian blue powder by Vauquelin who says that he

${ }^{1}$ St. Isidore of Spain wrote many books and he neentions this colour incidentally in an Etymological compilation. It is clear $v$ hat the early Latin authors were his thief authorities, and that he knew nothing practically about it, even his etymology in this case it at fault, as he does not tell us the meaning of Venetum, except by contrasting it with blue frit. It, however, appears to have been a grey or ill-defined colour, and by no means the brillant colour of Vestorianus. Vegetius iv, 37, has Colore Teneto qui marinis est fuctibus similis. Theophilus says that $\nabla$ eneda is black mixed with lime or white, and that it was used as a foundation for lapis lazuli. Theophilus, chapter Iv. Thus had the knowledge dropped out. 
is unable to tell its mode of manufacture whether by a wet or dry process.

H. de Fontenay in the Annales de Chimie, Série v, ii, p. 193, gives an account of the making of this material forming it into balls, but it was the pale colour not the deep violet blue.

Darcet working in Peligot's laboratory made some, but left no account of his process from commercial reasons, which, however, failed then as at present to introduce it.

F. Fouque, (Bull. Soc.des Mines de France,XII.36,)gives an account of a crystalline substance that he made himself which he called Vestorian blue. He says that it is a silicate of calcium and copper, and that potash and soda are unnecessary in its manufacture. It is therefore clear it is not the Egyptian blue. Some of it was exhibited at the Soiree of the Royal Society in 1889 as being the blue glaze of Egyptian pottery, but crystalline and glassy forms are not frit; while the combination of ingredients, treatment in the furnace, and the final result is quite different, nor can the material be changed to what it is claimed to be by any process.

Dr. W. J. Russell, F.R.S., has examined the Amarna specimens and his conclusions are given in a paper printed in Mr. Petrie's volume on Medum. He has also imitated them very successfully. He says that the most common of the blue pigments contain from 3 to 10 per cent of copper and that lime and sand were used with 10 per cent of a mixture of potassium and sodium carbonates. When the amount of copper is increased to 20 or 30 per cent and about an equal amount of lime is present, then the purple frits can be formed. But in the latter case the range of temperature is much more restricted and a longer exposure is required. He has succeeded in making at once large cakes of fine colour. His results are perfect and splendid. I have also succeeded in imitating many of the most beautiful hues from Gurob and elsewhere.

At Amarna the colours were mixed with egg albumen as described under Kahun. Acacia gum was largely used, and decaying left the colour pulverulent and loose. Several pots of paint were found to have a thick layer of gum overlying the colour which had settled at the bottom, these 
had not been exposed and the gum answered all the usual tests. Gum was employed for the painting of Akhenaten and the little princesses. It was also used on parts of the painted pavement. Mr. Petrie says that some of this pavement bore washing, albumen may have been used there, but there was evidence that it had been waxed also. Gelatine was used. Gelatine when first made is a jelly when cold, but on much boiling it loses the power of setting and becomes liquid. The same effect may be obtained by a lengthened exposure to the sun and air when it undergoes fermentation, becoming limpid; I have also found it employed with lime and gypsum to make gesso. At first gelatine was only employed thus, its use as glue was a later discovery. All very ancient woodwork was joined by pegs and in the drilling of holes and accurate fitting of parts the Egyptians were very clever. But as early as the XVIII. Dynasty skin was shredded and boiled until it became pulpy and thick in which state it was used to join woodwork together. Glue as we have it now, that is gelatine separated from insoluble and albuminous parts and then dried until needed, is a comparatively late invention.

Frit and powdered malachite were used, mixed with wax, for covering pottery and woodwork, but no elaborate decoration in this style has been found. Painted wood and pottery were frequently covered with a turpentine or liquid resin, as a varnish and then dried.

At Amarna, as well as in other places blue frit was used to decorate red coloured pottery, some of which was pale and some enhanced by the use of hæmatite. The effect of the bright blue patterns when well executed is very good. After painting the finished pot, the frit was set by gentle firing, then the colour did not come off nor did it shine like glaze. 